\title{
REORIENTASI KURIKULUM PAI DI MADRASAH: STUDI ANALISIS LANDASAN PENGEMBANGAN KURIKULUM PENDIDIKAN AGAMA ISLAM
}

\author{
${ }^{1}$ Muhammad Arbain \\ ${ }^{2}$ Badrut Tamam
}

\begin{abstract}
ABSTRAK
Pengembangan kurikulum pendidikan agama Islam harus memiliki landasan pijak yang kokoh dalam pengembangannya.Landasan pengembangan kurikulum pendidikan agama Islam tersebut merupakan komponen yang penting dalam menjaga bangunan pendidikan Islam tetap berdiri tegak. Oleh karena itu, para pengembang kurikulum pendidikan agama Islam perlu menetapkan landasan dalam pengembangan kurikulum yang akan mereka gunakan di Madrasah. Penelitian ini menggunakan analisisdeskriptif dalam mengembangkan kurikulum Pendidikan Agama Islam.Dari hasil analisis didapatkan ada tujuh landasan yang dapat digunakan dalam pengembangan kurikulum Pendidikan Agama Islam di Madrasah yaitu; landasan teologis (agama), landasan filosofis, landasan ideologis, landasan psikologis, landasan sosiologis, landasan IPTEK dan landasan organisatoris. Dengan adanya landasan tersebut, lembaga pendidikan Islam (Madrasah) dapat memiliki landasan atau pijakan yang kokoh dalam menentukan arah lembaga pendidikannya serta dapat tetap berdiri tegak dari berbagai gempuran arus globalisasi. Landasan tersebut setidaknya dapat menjadikan lembaga pendidikan Islam (Madrasah) berorientasi pada masa depan dalam pengembangan peradaban Islam baik secara nasional maupun internasional.
\end{abstract}

Kata Kunci : Landasan Pengembangan Kurikulum, Kurikulum Pendidikan Agama Islam, Madrasah.

\footnotetext{
${ }^{1}$ Dosen Luar Biasa Prodi Tarbiyah dan Drafter Lembaga Penjaminan Mutu IAIN Samarinda

${ }^{2}$ Dosen IAIN Samarinda Fakultas Tarbiyah dan Ilmu Keguruan (FTIK)

38 | Volume 13, No. 1, Januari-Juni 2017
} 


\begin{abstract}
The conflict between group of sufism and anti-sufism have been going on since classical times. The root of the problem between the two groups is not only based on normative issues, but is also related to the sociological problems. On a more formal level, the role of the State in supporting or rejecting the sufi group also became its own record in the history of Islamic civilization. This paper tries to see criticism method used by anti-sufi groups, in this case represented by the thought of Ibn Taymiyah. This paper is aimed to critically analyze Ibn Taymiyah's thought of Sufism by examining the literature related to the track record of Ibn Taymiyah's thought about with Sufism and the methodology it offers. Criticism on the instutionalized group (tarekat) becomes the focus of discussion in which regarded as the starting point of the entire perversion of sufi practices. The result shows that there are three main points of Ibn Taymiyah commentary. Those are tariqah (devotional orders) institution, the knowledge resources and the doctrine of duality of inward-outward and sharia-haqiqah. Ibn Taymiyah commented on these using the analysis method of hadith experts (literalist-scripts) by self-sufficient reading the Sufis works and conducting structuralist studies of the Sufi texts.
\end{abstract}

Keywords: madrasah, Islamic religious education curriculum 


\section{PENDAHULUAN}

Jejak anti sufi sebenarnya merupakan panorama peradaban dalam agama Islam. Selalu ada kelompok dan kontra dalam memandang entitas Sufi. Fenomena ini tak pernah hilang, meski segala cara pernah dilakukan oleh sarjana-sarjana muslim klasik-kontemporer untuk menciptakan nuansa saling memahami. Walaupun hasilnya seringkali sebaliknya.

Beberapa waktu lalu, masyarakat Muslim dikagetkan oleh sebuah video yang beredar di internet dan disiarkan secara massif di channel televisi Timur tengah: kelompok yang menamakan diri Salafi ${ }^{3}$ atau biasa disebut "Wahhabi" oleh lawan ideologi mereka, dengan keji meluluh lantakkan sebuah kuburan seorang ulama di Libya sekaligus masjid di sampingnya dan membakar perpustakaan pribadi yang menyimpan kekayaan turäs Libya.

Ulama Sunni sempat bereaksi keras dan mengecam tindakan itu, termasuk mufti Mesir ketika itu Dr. Ali Gomaah dan Syekh AlAzhar Dr. Ahmad At-Tayyeb. Meski sebenarnya, dari kejadian tersebut bisa ditelusuri dialektika sejarah yang sangat panjang, yaitu kedekatan tarekat-tarekat Sufi Libya dengan rezim Kaddafi. Pemerintahan Kaddafi yang digulingkan para revolusioner bisa dilihat sebagai pelampiasan kecemburuan terpendam dari kelompok non Sufi, yang konon disubordinatkan oleh rezim yang berkuasa hampir 30 tahun lebih itu.

"Persaingan" antara kaum Sufi dan anti Sufi ${ }^{4}$ semenjak masa klasik sudah menjadi sajian wajib dalam lembar buku sejarah. Inklinasi sufistik, yang diyakini oleh beberapa pakar sosiologi-psikologi agama

\footnotetext{
${ }^{3}$ Kelompok yang sebenarnya berafiliasi pada seorang dai, Muhammad bin Abdul Wahhab, yang kemudian terlibat kontrak politik dengan Raja Saud, pendiri Dinasti Karajaan Saudi sekarang.

${ }^{4}$ Gerakan anti-Sufi Nusantara dengan membawa bendera Wahhabiyah ditandai dengan terbitnya sebuah Jurnal Salafy 1995-2000. Institusi Wahhabi Nusantara pertama diresmikan pada 1990-an dengan pemimpin tertinggi Jakfar Umar Thalib, murid Muqbil bin Hadi Al-Wadi'i yang pernah berguru pada Al-Albani dan Abdul Aziz b. Baz (lihat: Michael Laffan, National Crisis and The Representation of Traditional Sufism in Indonesia: The Periodicals Salafy and Sufi, dalam kompilasi buku bertajuk Sufism and The 'Modern' in Islam, Ed. Martin V. Bruinessen \& Julia Day Howell, I. B. Tauris \& Co Ltd, London, 2007, h. 152)

40 | Volume 13, No. 1, Januari-Juni 2017
} 
dan antropologi, akan terus ada dalam setiap agama-agama di dunia. Trend hidup asketik seakan menjadi sisi lain kehidupan manusia. Sepanjang perjalanan manusia, terlepas apapun agama dan ideologi yang dikukuhinya, akan selalu menampilkan sosok yang 'nyaman' hidup secara asketis. Termasuk diantaranya, lahirnya sosok-sosok Sufi dalam Islam. ${ }^{5}$

Keluhuran budi, kesalehan dan gaya hidup sederhana tentu saja menjadi kharisma tersendiri untuk menarik simpati masyarakat. Para Sufi yang menyucikan jiwanya dengan beragam inisiasi dan bekerja untuk masyarakat tanpa pamrih adalah sekian dari magnet yang dimiliki kaum Sufi. Fakta ini tentu menimbulkan kecemburuan sosial dari kelompok lain. Sehingga tak heran, jika kita saksikan pelecehan, penyiksaan dan bahkan eksekusi mati seringkali menimpa kaum Sufi. Beragam label sesat, pelaku bid'ah, hingga syirik dan kafir seringkali menghiasi karya-karya anti Sufi yang menyoroti praktik ritual, tradisi hingga menghakimi keyakinan mereka. Padahal sesuatu yang ada dalam relung hati terdalam hanya Allah Swt yang Maha Mengetahui.

\section{PINTU TERBUKA ANTI SUFI}

Kecenderungan anti sufi sebuah negara dengan yang lainnya sangat variatif dan dalam skala yang tidak sama. Ada yang biasa-biasa saja, ada pula yang ekstrim. Dalam beberapa literatur disebutkan, bahwa Ibn Taimiyah adalah seorang intelektual abad pertengahan yang bisa dibaca secara serius dan mendalam sebagai poros anti Sufi. ${ }^{6}$

Ada banyak alasan mengapa dalam tulisan ini sosok Ibn Taimiyah dipilih sebagai simbol anti Sufi paling representatif. Pertama, karena karya-karyanya mengilhami aliran ini, sementara ulama anti Sufi lainnya hanya sebatas gerakan tanpa karya nyata. Kedua, Ibn Taimiyah adalah kulminasi dari aliran anti Sufi sebelumnya. Ketiga, Ibn Taimiyah termasuk di antara ulama yang

\footnotetext{
${ }^{5}$ Samuli Schielke \& Georg Stauth, Dimensions of Locality; Muslim Saint, Their Place and Space, Gutenberg Univ., Jerman, 2008, h. 6

6 Meski satu abad sebelumnya ada Ibnu Aqil dan muridnya Al-Jauzi yang melancarkan kritik pedas, namun mereka hidup di masa tasawuf falsafi belum matang. Ibnu Taimiyah kemudian melanjutkan proyek mereka hingga menyentuh konsep wahdatul wujud.
}

41 | Volume 13, No. 1, Januari-Juni 2017 
mengalami langsung pergesekan keras dengan kaum Sufi hingga di penjara di Alexandria gara-gara fatwa yang menyalahi jumhur tentang "larangan berziarah kecuali ke tiga masjid". Keempat, Ibn Taimiyah menjadi referensi utama atau mungkin satu-satunya bagi kelompok Salafi-Wahhabi ${ }^{7}$ dalam proyek anti Sufi, yang mereka teriakkan di seantero dunia Islam atas nama "purifikasi agama".

Sebelum Ibn Taimiyah, karya Ibn Al-Jawzi (w. 597 H) dengan Talbis Iblis-nya dikenal pula sebagai naskah pemikiran yang getol memperjuangkan gerakan anti-Sufi, meski masih bersifat parsial dan belum matang ${ }^{8}$. Kritik terhadap sufi yang sangat fundamental dan integral, menyentuh hampir semua lapisan sensitif tasawuf, dapat ditemukan pada karya Ibn Taimiyah. Selain itu, tentu saja pengalaman pribadi Ibn Taimiyah yang sangat heroik dalam memperjuangkan nilainilai yang diyakininya sebagai "tradisi Salaf". Ibn Taimiyah rela diperlakukan secara terhina dan disiksa demi ideologi yang diyakini. Kenyataan ini tentu saja mengagumkan bagi setiap pengikutnya.

Muhammad Abdurrahman Al-Uraifi, yang menulis disertasi doktoral berjudul "Sikap Ibn Taimiyah Terhadap Kaum Sufi"', dan Musthafa Hilmi, seorang penulis produktif yang bersimpati pada Ibn Taimiyah, bersikeras bahwa Ibn Taimiyah bukan seorang anti Sufi. Mereka lebih suka menyebut Ibn Taimiyah sebagai kritikus Sufi. Tapi setidaknya, bagi saya, kritik yang dilancarkan Ibn Taimiyah telah membuka pintu bagi kelompok anti-Sufi. Wahhabiyah sendiri memandang Ibn Taimiyah sebagai ikon kaum Salaf, dan dalam tataran yang paling radikal dia dianggap sebagai representasi kedua setelah imam Ahmad bin Hambal dalam menyuarakan mazhab Ahlussunnah wal Jama'ah (Aswaja).

\footnotetext{
${ }^{7}$ Lihat misalnya karya Muhammad bin Abdul Wahhab yang memakai argumentasi serupa dengan yang dipakai Ibn Taimiyah. Kenyataan ini memang naif, karena Wahhabi mengklaim diri sebagai kelompok anti-taklid tapi membebek pada Ibn Taimiyah dan beberapa imam mereka dalam banyak kasus.

${ }^{8}$ Dia menyisakan Bab X-XIII secara khusus untuk mengkritisi tasawuf (Al-Jauzi, Talbis Al-Iblis, Maktabah Al-Mutanabbi, cet II, 1368 H, h. 157-selesai

9 Buku ini akan saya jadikan rujukan utama karena pertimbangan spesialisasi kajiannya yang sangat detail menelusuri turast Ibn Taimiyah terkait komentar dan sikapnya terhadap kaum Sufi. Buku ini konsentrasi pada kajian teks Ibn Taimiyah secara langsung.
}

42 | Volume 13, No. 1, Januari-Juni 2017 


\section{PAKAR HADIS DAN POLEMIK ASWAJA ${ }^{10}$}

Untuk meloloskan klaim sebagai suara terpercaya yang mewakili Aswaja, Ibn Taimiyah mengemukakan sebuah adagium "semakin jauh seseorang dari sunnah (hadis-hadis Rasul Saw.) maka semakin dekat dengan bid'ah dan kesesatan"11. Adagium ini kemudian secara sadar dijadikan standarisasi "siapa sebenarnya yang paling berhak mengaku sebagai Aswaja (baca: Sunni)". Tak diragukan lagi, bahwa pakar hadis sebagai penjaga turast hadis Nabi Saw. adalah representasi paling dekat dengan Sunni.

Sebelum melanjutkan kajian anti-Sufi, penting rasanya menghadirkan adagium di atas, karena kesadaran itulah yang hingga detik ini masih dikukuhi oleh kalangan Wahhabi untuk menyebut diri sebagai "Sunni" atau "Salafi". Sekilas pembaca akan merasa bahwa adagium ini benar adanya: pakar Hadis - perspektif Ibn Taimiyahadalah representasi sah Sunni satu-satunya. Sementara kelompok ulama yang lain: pakar fikih, kalam, gramatika bahasa, tafsir, sejarah dan terutama tasawuf dan filsafat jauh dari nilai-nilai ulama salaf. Dia sama sekali tak menyadari bahwa pakar hadis abad I-III juga banyak yang melakukan ritual dan suluk sufi. Mereka juga mendalami ilmu kalam sebelum filsafat diterjemah ke dalam bahasa Arab.

Abdullan bin Abbas pernah diperintah khalifah Ali bin Abu Thalib untuk menghadapi sekte Khawarij. ${ }^{12}$ Hasan Al-Bashri, salah seorang tabiin terbaik, memang dikenal tak mudah berbicara mengenai kajian ilmu kalam di depan umum. Tapi ada sebuah data menyebutkan bahwa, ulama yang diperebutkan sekte-sekte Islam, termasuk Wahhabiyah, terbiasa mengumpulkan murid-murid pilihannya dalam sebuah ruangan khusus dan tertutup untuk mengkaji ilmu kalam. Perdebatannya dengan Washil bin Atha' mengenai "takdir Tuhan"

\footnotetext{
10 Ahlussunnah Wal Jama'ah adalah kelompok yang diyakini mendapat label "selamat" dari Nabi Saw. Karenanya tak heran semua kelompok dan sekte Islam memperebutkannya. Nama Aswaja menjadi sangat prestise dan berkelas.

${ }^{11}$ Muhammad Abdurrahman Al-Uraifi, Mauqïf Ibn Taimiyah min As-Süfiyah, Vol I, cet I, Dar Al-Minhaj, Riyadl, 1430 H, h. 86

${ }^{12}$ Hasan As-Syafi'i, Al-Madkhal Ila Dirasāt 'Ilmi Al-Kalām, Maktabah Wahbah, Kairo, cet II, 1991, h. 62
}

43 | Volume 13, No. 1, Januari-Juni 2017 
adalah bukti lainnya. ${ }^{13}$ Mereka semua adalah pakar dalam hadis dan termasuk ulama salaf.

Pakar hadis yang dimaksud Ibn Taimiyah sebagai representasi Aswaja menjadi semakin ambigu tatkala kita merujuk buku-buku 'Ulüm al-Hadis', yang secara ketat memberi kriteria tertentu mengenai seseorang disebut sebagai "muhaddis" (pakar hadis). Selain tranmisi sanad yang harus dimiliki seorang muhaddis, personifikasi sebagai orang yang kuat hafalan dan memiliki catatan dokumentasi hafalan hadisnya juga sangat penting. ${ }^{14}$ Bila semua kriteria yang tertulis dalam disiplin ilmu hadis tak terpenuhi maka seseorang belum bisa diberi predikat "muhaddis": dalam pemahaman Ibn Taimiyah sendiri jauh dari definisi Sunni-Aswaja.

Saya tak pernah meragukan kekuatan hafalan Ibn Taimiyah, karena seperti disinggung oleh murid-muridnya ${ }^{15}$ : Ibn Taimiyah sangat kuat hafalannya. Bahkan sebagian mereka dengan nada fanatik menyebutkan bahwa apapun yang tidak dihafal Ibn Taimiyah berarti bukan hadis ${ }^{16}$. Semua klaim ini disinyalir sebagai legitimasi bahwa Ibn Taimiyah adalah seorang pakar hadis dalam pemaknaan sesungguhnya. Namun sebuah kajian Ibrahim Uqaili dalam bukunya Takāmul AlManhaj Inda Ibni Taimiah yang menyebutkan bahwa Ibn Taimiyah menulis sejumlah besar karya-karyanya di pengasingan atau penjara patut dipertimbangankan. Dia, tulis Uqaili, acapkali menulis tanpa melakukan verifikasi pada buku atau pada ulama lain yang hidup di masanya. ${ }^{17}$

Data ini saya hadirkan tanpa ada maksud mencederai pribadi Ibn Taimiyah, namun semata-mata pertimbangan ilmiah bahwa Ibn Taimiyah yang memposisikan pakar hadis sebagai satu-satunya kelompok ulama yang merepresentasikan Sunni-Aswaja ${ }^{18}$ berbalik

\footnotetext{
${ }^{13} \mathrm{Ibid}$, h. 65

${ }^{14}$ Nuruddin 'Itr, Manhaj An-Naqd fi 'Ulüm Al-Hadis, Dar Al-Fikr, Beirut, cet XXIII, 2008, h. $87-88$

${ }_{16}^{15}$ Seperti Ad-Dzahabi, Al-Barzali, Al-Mazzi dll.

16 Ibrahim Uqaili, Takāmul Al-Manhaj 'Inda Ibni Taimiyah, The International Institute of Islamic Thought, Herdon-Virginia, cet I, 1994, h. 86

${ }^{17}$ Ibid, h. 104

18 Kelak dengan legitimasi ini dia mengeluarkan semua sekte Islam dan menyesatkannya, termasuk Jahmiyah, Kulabiyah, Asya'irah, Maturidiyah, Qadariyah. Jabariyah, Murjiah, Rafidlah, Sufiyah, Muktazilah dan Musyabbihah. Kemudian 44 | Volume 13, No. 1, Januari-Juni 2017
} 
arah mengeluarkan dirinya sendiri dari barisan pakar hadis. Ibn Taimiyah tak cukup kualifikasi untuk disebut sebagai muhaddis karena ada satu syarat urgen yang tak dimilikinya: dabtu al-kitābah (tulisan dokumentasi hafalan hadis). Belum lagi, ketegasannya memilih sikap anti-takwil dengan maksud menutup pintu perselisihan dan perbedaan pendapat.

Kriteria adagium yang telah disebut di atas bisa jadi benar, tapi tak perlu mengeluarkan ulama-ulama yang memiliki kecenderungan berbeda dengannya. Bagaimanapun, pakar fikih, kalam, gramatika bahasa, tafsir, sejarah, tasawuf dan filsafat yang dikeluarkan dari barisan Sunni-Aswaja oleh Ibn Taimiyah juga menafsirkan dan mengekplorasi pengetahuannya dengan berpijak pada Al-Quran-Hadis. Jika tidak, maka Ibn Taimiyah sedang melakukan penyempitan pemahaman keagamaan dengan dalih menghindari perbedaan pendapat sekaligus harus siap menyalahi jumhur; mengingat komposisi SunniAswaja terdiri dari semua pakar yang dikeluarkan Ibn Taimiyah. Aswaja dalam kriteria yang disebut Nabi Saw. sebagai as-sawad ala'zam (golongan mayoritas) tak akan pernah terwujud bila memaksa memakai penafsiran Ibn Taimiyah. ${ }^{19}$

\section{TASAWUF DALAM KESADARAN IBN TAIMIYAH}

Penjelasan panjang lebar mengenai pakar hadis di atas dimaksudkan agar pembaca menyadari bahwa Ibn Taimiyah dan kelompok anti-Sufi yang datang setelahnya, dalam semua kritiknya memakai pisau analisis pakar hadis (meski saya mengidentifikasi adanya kerancuan tentang pakar hadis yang mana yang dimaksud Ibn Taimiyah. Saya lebih suka menyebutnya sebagai metode "literalisskriptualis").

menutup pintu Islam yang benar hanya untuk Ahlussunnah, yang diasumsikan sebagai pengikut imam Ahmad b. Hambal dan orang-orang yang searah-pemikiran dengannya (Al-Uraifi, Op cit, h. 85-86)

${ }^{19}$ Dr. Mahmud Yunus, seorang sarjana Al-Azhar asal Indonesia pada tahun 70-80 an pernah melakukan riset dan menyimpulkan bahwa prosentase sekte kalam Asy'ariMaturidi adalah yang terbanyak di dunia Islam. Sementara di Indonesia terdapat 40 lebih tarekat Sufi dan di Mesir terdapat sekitar 70 tarekat Sufi dengan jutaan pengikut, yang diestimasi sesat oleh kredo yang dibangun Ibn Taimiyah. Bagaimana anda memahami fenomena penyesatan semacam ini?!

45 | Volume 13, No. 1, Januari-Juni 2017 
Ibn Taimiyah dan pengagumnya tak pernah merasa perlu memasuki "ruang pribadi" Sufi untuk mengenal dan mengkritisi mereka. Dia mencukupkan diri hanya dengan membaca sekilas karya sufistik dan melakukan kajian strukturalis teks-teks sufistik, sekali lagi, dengan berpijak pada ideologi literalis yang sudah tertanam kuat. Setiap teks yang dibaca, bagi kelompok anti-Sufi, hanya memendarkan satu makna saja. Kemungkinan-kemungkinan makna yang sebenarnya bisa memendar dari teks simbolis Sufi tak pernah dipertimbangkan: sebuah pembacaan yang sepihak dan sangat ideologis.

Kenyataan ini semakin menyedihkan tatkala Ibn Taimiyah hanya bersandar dan mengandalkan hafalannya atau jawaban terburuburu dari sebuah pertanyaan yang diajukan seseorang ${ }^{20}$ seperti terekam dalam Majmū' Fatāwā-nya. Tak jarang Ibn Taimiyah dihampiri keraguan dengan apa yang akan ditulisnya, semisal tersirat dalam pemakaian terma "azunnu" (saya menduga), ketika dia mencoba mengidentifikasi kemunculan tasawuf dan takaya (pondok sufi) di

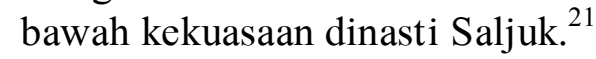

Benar, Ibn Taimiyah memang tidak membabi buta dalam mengkritik Sufi dan masih mengapresiasi mereka selama memenuhi tiga syarat yang diajukannya: pertama, melakukan semua kewajiban beragama dan menjauhi segala yang dilarang oleh syariat. Kedua, tidak melakukan ritual yang sifatnya mengada-ada dan tak memiliki dasar syariat (bid'ah). Ketiga, mau hidup sederhana dan menjauhi gaya hidup yang berlebih. Tanpa memenuhi ketiga syarat itu, Ibn Taimiyah menyebutnya sebagai Sufi jargonis. ${ }^{22}$

Dia juga masih mengapresiasi beberapa tokoh sufi, semisal AlHarist Al-Muhasibi $(243 \mathrm{H})$, Al-Juneid Al-Baghdadi $(297 \mathrm{H})$ dan Abdul Qadir Al-Jilani $(560 \mathrm{H})$ dll. Dia bisa berdamai dengan ulama Sufi yang dianggapnya tidak nyeleneh dan mengeluarkan statemen ekstatif, bahkan jasad Ibn Taimiyah sendiri di kebumikan di pekuburan Sufi. Dia juga memberi nama kelompok Sufi jalur ini dengan "tasawuf syar'i" ${ }^{23}$; sebuah nama yang sebelumnya tak pernah digagas bahkan

\footnotetext{
${ }^{20}$ Ibrahim Uqaili, Op cit, h. 105

${ }^{21}$ Al-Uraifi, Op cit, h. 236

${ }^{22}$ Ibid, h. 237-238

${ }^{23}$ Dalam buku yang ditulis Alwi Shihab berjudul "Tasawuf Sunni dan Falsafi", dia mengklasifikasi kecenderungan sufistik dalam dua kelompok besar seperti tertulis di 46 | Volume 13, No. 1, Januari-Juni 2017
} 
oleh kaum Sufi sendiri karena memang Sufisme adalah satu kesatuan dengan formulasi yang beragam. Visi sufistik semuanya sama: menginisiasi diri ke dalam sebuah suluk Sufi yang ketat untuk membentuk mental dan karakter yang berakhlak mulia. ${ }^{24}$

Perbedaan yang tampak di luar dalam mendidik salik adalah sebentuk konsekuensi dari penguraian psikologi manusia yang memang tidak sama antara satu dengan yang lainnya. Sehingga dalam karya-karya sufistik kita mengenal istilah "ragam tarekat Sufi sesuai ragam psikologi manusia, pengalaman spritual setiap mursyid, perbedaan adat istiadat dan letak geografis". ${ }^{25}$ Semua cara yang ditempuh master Sufi dalam mendidik muridnya memang mengkombinasikan warisan kenabian sekaligus hasil ijtihad yang tidak menyalahi aturan syariat. ${ }^{26}$ Kombinasi semacam itu dianggap penting selama bisa meningkatkan intensitas kedekatan seseorang pada Tuhannya. Terbukti, Nabi Saw. selalu mempertimbangkan sisi psikologis sahabatnya ketika memberi nasehat; ada yang diperintah agar meningkatkan bakti pada orang tua, menambah sedekah, menyuruh agar lebih bersabar, hingga berjihad di medan perang. Memaksa suluk Sufi hanya hadir dalam satu bentuk, sama dengan menyalahi fitrah manusia itu sendiri.

Bagi Ibn Taimiyah, suluk Sufi harus sesuai dengan bentuk dan format yang digagas kaum salaf persis seperti yang dia tangkap melalui pembacaan literalis terhadap teks-teks hadis. Ritual sufistik, keyakinan kasyfiyat (terbukanya alam metafisik) dan doktrin kewalian beserta tingkatan-tingkatannya adalah bid'ah. Sehingga semua usaha kaum Sufi untuk mengembalikan asas dan akar tardisi mereka pada AlQuran atau hadis-baik secara langsung maupun dalam bentuk

judul. Klasifikasi semacam ini boleh-boleh saja untuk sekedar mengidentifikasi kecenderungan masing-masing tokoh sufi.

${ }^{24}$ Al-Ghazali, Al-Munkidz min Ad-Dlalal, dalam kompilasi buku Majmuat Rasa'il Al-Ghazali, Dar As-Syatibi, Kairo, cet I, 2010, h. 25-26

${ }^{25}$ Muhammad Najmuddin Al-Kurdi, Ad-Dalail Al-Aliyah, Dicetak oleh pengarang, Kairo, cet I, 2008, h. 43-44

${ }^{26}$ Julia Day Howell \& Martin V. Bruinessen, Sufism and The 'Modern' in Islam, I. B. Tauris \& Co Ltd, London, 2007, h. 7

47 | Volume 13, No. 1, Januari-Juni 2017 
interpretasi-selalu dimentahkan oleh Ibn Taimiyah dan kelompok anti Sufi. ${ }^{27}$

\section{TAREKAT SEBAGAI BIANG KESESATAN SUFI}

Mayorias anti Sufi, terutama Ibn Taimiyah, memandang terlembaganya tasawuf dalam institusi tarekat sebagai titik awal yang paling menentukan dari parade kesesatan, bid'ah, kesyirikan dan lelaku zindik dalam aliran Sufi. Karena dari sana, muncul ritual dzikir berjemaah (baik dengan suara keras maupun pelan) yang tak pernah terjadi di masa salaf, tradisi baiat sebagai simbol perjanjian salik untuk memperbaiki diri, hingga tradisi menghormati guru tarekat yang dianggap melampaui batas kewajaran.

Belum lagi, bacaan wirid yang dijalani seorang salik dalam kesehariannya. Kelompok anti Sufi mendramatisir suluk Sufi dengan mengatakan bahwa mereka lebih mencintai wiridnya dari pada AlQuran. Ulama salaf di masa sahabat sibuk berjihad di medan perang, bukan menyibukkan diri dengan ritual semacam itu. ${ }^{28}$ Konsep tauhid rububiyah yang dikembangkan Ibn Taimiyah menjadi senjata paling jitu dalam melibas tradisi yang berlaku dan diyakini dalam komunitas Sufi. Sehingga tawassul, istighasah, ziarah kubur adalah sekian dari bentuk kesesatan Sufi yang lainnya.

Dalam buku-buku yang ditulis Ibn Taimiyah, seperti saya baca dari disertasi Al-Uraifi, semua tarekat Sufi adalah sesat tanpa ada pengecualian, meski memang kadar kesesatannya tidak satu level. Dari semua label sesat itu, Ibn Taimiyah hanya memakai satu logika: institusi semacam itu tak pernah ada di masa Salaf maka aktivitas dan tradisi yang dikembangkan juga sesat. Padahal pegiat tarekat Sufi sudah berkali-kali melakukan pembelaan bahwa tradisi yang mereka

\footnotetext{
${ }^{27}$ Sarjana Islam klasik-kontemporer sudah menulis ribuan buku dengan argumentasi ilmiah untuk menegaskan hal ini. Namun kelompok anti-Sufi seakan menutup mata dan telinga karena terpaku pada teks-teks hadis tanpa pernah mau mengkomparasikan dengan teks hadis lainnya atau menafsirkan sesuai kaedah yang berlaku. Maka ada benarnya juga jika kelompok anti-Sufi ini disebut sebagai abdun nash "budak teks".

${ }^{28}$ Al-Uraifi, Op cit, h. 246

48 | Volume 13, No. 1, Januari-Juni 2017
} 
lakukan memiliki akar yang kuat, baik dari Al-Quran maupun hadis Nabi Saw., entah secara eksplisit maupun implisit.

Kelompok anti Sufi memang bersikeras bahwa apapun pembelaan yang dilakukan akan tetap sia-sia, mengingat tak ada satu nas șarih (teks yang amat jelas) yang bisa melegitimasi adanya tarekat beserta tradisi yang dikembangkannya. Bahkan kalaupun ada, semisal hadis mengenai "level kewalian", mereka akan segera menyebutnya sebagai hadis buatan atau sanadnya lemah. ${ }^{29}$ Sehingga menjadi mafhum, ketika Syekh Mahmud Al-Ghurab menyindir dalam mukaddimah bukunya yang memuat pembelaan terhadap Ibn Arabi, yang dikafirkan oleh Ibn Taimiyah, bahwa tak ada seorang pun yang bisa mengaku menguasai semua tradisi hadis kenabian, termasuk Ibn Taimiyah. ${ }^{30}$ Klaim representasi ulama salaf paling valid adalah bentuk dari kepongahan intelektual.

Dalil tekstualis telah mengeras dan membatu dalam kesadaran kelompok anti-Sufi. Sehingga pertimbangan sejarah acapkali dikesampingkan. Lembaga tarekat Sufi yang sebenarnya sudah ada semenjak masa sahabat dan kemudian mapan di abad V-VII, tak pernah dipertimbangkan. ${ }^{31}$ Fanatisme terhadap guru sebenarnya lebih akut dalam tubuh anti-Sufi ${ }^{32}$ : mereka menutup diri dari pendekatan kesejarahan dan tak pernah mengenal pendekatan psikologisantropologis yang berkembang di era kontemporer. Argumentasi

29 Muhammad Hilmi Abdul Wahhab, Wulāt wa Awliā As-Sultah wa AlMutașawwifah fi Islam Al-Aṣr Al-Wasiț , As-Syabakah Al-Arabiyah li Al-Abhast wa An-Nasyr, Beirut, cet I, 2009, h. 94

${ }^{30}$ Mahmud Al-Ghurab, Syarh Kalimat Sufiyah; Ar-Rad 'Ala Ibn Taimiyah, Matba'ah Nadlr, cet II, 1993 h. 7

${ }^{31}$ Baca abstraksi Ali Sami An-Nassar dalam Nasy'at Al-Fikr Al-Falsafi fi Al-Islam, Dar As-Salam, Kairo, Vol III, cet I, 2008 (bandingkan: Nicholson, As-Sufiyah fi AlIslam, diarabkan oleh Nuruddin Syarribah, Maktabah Al-Khanji, Kairo, cet II, 2002, h. 12-13)

${ }^{32}$ Gejala ini ditengarai sebagai salah satu faktor yang mendorong seseorang menjadi kafir. Ibn Taimiyah berulang kali memakai qiyas tamsil yang bersifat memaksa dan tak sesuai dengan fakta di lapangan. Untuk contoh: "seorang salik memandang gurunya layaknya umat Kristiani memandang Isa Al-Masih" (Al-Uraifi, Op cit, h. 527/532). Barangkali, akibat sebuah buku bantahan yang ditulisnya untuk pakar retorika "Ar-Rad 'Ala Al-Mantiqiyin", di sana Ibn Taimiyah berpendapat bahwa qiyas tamsil sejajar dengan qiyassyumul (komprehensif); keduanya sama-sama mengindikasikan "keyakinan". Dia berusaha meruntuhkan hipotesa pakar mantiq bahwa qiyas tamsil hanya sampai pada level "praduga" (lihat: Uqaili, Op cit, h. 349)

49 | Volume 13, No. 1, Januari-Juni 2017 
historis anti-Sufi yang ditulis secara singkat dan sempit oleh Ibn Taimiyah sudah cukup bagi mereka. Padahal mereka tahu pasti bahwa dia menulisnya dalam situasi yang labil dan dengan referensi yang amat sangat terbatas karena mendekam di penjara.

Mereka tak pernah mendengar bahwa pakar sosiologi modernkontemporer di tahun 70-80 an harus merubah hipotesa yang sebelumnya dikukuhi: "modernitas selalu searah dengan sekulerisme", gara-gara perkembangan institusi tarekat di dunia Islam dan di barat. Tarekat Sufi telah berperan besar dalam meningkatkan kesadaran beragama di tengah komunitas manusia modern yang individualis. ${ }^{33}$ Tak hanya itu, komunitas Sufi yang bernaung di bawah institusi tarekat turut serta meredam gejolak radikalisme agama, baik di dunia Islam maupun di barat. ${ }^{34}$ Dan yang paling menakjubkan adalah kesimpulan para pakar sosiologi agama dekade ini yang mengatakan bahwa tarekat Sufi adalah institusi yang paling bisa berdamai dengan modernitas karena ritual keagamaan yang sifatnya "structure of everyday life" dengan format aktivitas yang natural ${ }^{35}$ dan terbuka untuk semua elemen manusia modern, dari rakyat biasa hingga birokrat.

Dalam pengamatan Al-Uraifi, Ibn Taimiyah merujuk pada sekitar 43 buku primer tasawuf. Ini membuktikan bahwa Ibn Taimiyah sangat menjaga amanat ilmiah sekaligus serius mengkaji Sufisme. ${ }^{36}$ Namun Al-Uraifi tak menyebutkan apakah Ibn Taimiyah menulis proyek kritik sufismenya - di Al-Farqu Baina Awliya Ar-Rahman wa Awliya As-Syaithan dan yang tercecer di berbagai bukunya-ditulis dengan merujuk langsung pada buku primer tersebut atau sekedar bersandar pada "ingatan" samata. Dari dua kali audiensi yang diadakan aktivis Said Aqil Siraij Center (SASC) dengan Syekh Mahmud AlGhurab di Mesir, dia menyimpulkan penelusurannya selama bertahuntahun, bahwa sebenarnya Ibn Taimiyah tidak pernah membaca karya Ibn Arabi-salah seorang tokoh Sufi yang dikritik Ibn Taimiyah-,

\footnotetext{
${ }^{33}$ Jhon O. Vall, Contemporary Sufism and Current Social Theory, dalam kompilasi buku bertajuk Sufism and The 'Modern' in Islam, Ed. Martin V. Bruinessen \& Julia Day Howell, I. B. Tauris \& Co Ltd, London, 2007, h. 282-283s

${ }^{34}$ Ibid, h. 287

${ }^{35}$ Ibid, h. 289

${ }^{36}$ Al-Uraifi, Op cit, h. 133

50 | Volume 13, No. 1, Januari-Juni 2017
} 
atau pernah membacanya tapi lupa, atau dia memang membaca tapi manuskrip yang distorsif. ${ }^{37}$

Penelitian filologis yang dilakukan al-Ghurab menemukan logikanya jika kita mau mempertimbangkan perjalanan hidup Ibn Taimiyah yang terpaksa keluar-masuk penjara serta kesibukannya berdebat dengan lawan ideologisnya. Frekuensi debat yang padat, menurut Al-Ghazali dalam Ihya', akan menumbuhkan benih-benih sifat negatif dalam diri pelakunya. Makanya, kaum Sufi menghindari tradisi ini sebisa mungkin. Karena watak dasar debator adalah bagaimana memenangkan argumentasinya dan mempertahankan ideologi yang diyakininya, meski terkadang harus menghadirkan argumentasi yang terlihat memaksa dan naif karena menggenaralisir suatu masalah atau kasus tertentu.

Sekilas, pengagum Ibn Taimiyah memang merasa empati pada kisah hidupnya. Mereka seakan tak pernah tahu bahwa bukan hanya dia yang pernah merasakan dinginnya dinding penjara. Ribuan ulama dan kaum Sufi pernah mengalami hal serupa atau bahkan lebih. ${ }^{38}$ Derita dan nasib seorang ulama tak ada kaitannya dengan kebenaran dan keshalehan, tapi lebih pada ketegangan politik semata. Perbedaan yang paling mendasar: Ibn Taimiyah terlihat semakin beringas mengecam lawan ideologisnya sementara kaum Sufi yang mengalami hal serupa malah melupakan dan berserah pada Allah Swt. tanpa ada niat membalas. Memang Ibn Taimiya secara lisan pernah berkata "Siapapun yang menyakiti dan menfitnahku maka saya merelakannya." Tapi teror pemikiran dan label sesat yang ditulis dalam buku-bukunya adalah hal berbeda yang perlu dicermati.

Saya menghormati pribadi Ibn Taimiyah yang mendalami hampir semua disiplin ilmu yang berkembang di masanya. Meski dia tegas hanya bersimpati pada satu kelompok: ulama hadis yang

${ }^{37}$ Bisa juga dibaca di mukaddimah Rasa'il Ibn Arabi yang ditulis Al-Ghurab, Dar Shader, Beirut, cet I, 1997, h. 10 (bandingkan juga dengan Al-Ghurab dalam ArRadd Ala Ibn Taimiyah, h. 9)

${ }^{38}$ Baca: Al-Yawaqit wa Al-Jawahir karya As-Sya'rani yang sedikit merekam fitnah, penyesatan, penyiksaan, dan bahkan pembunuhan yang menimpa beberapa ulama. Diantaranya keempat imam mazhab fikih, Abu Yazid Al-Busthami, Dzunnun AlMishri, Sahl At-Tusturi, Al-Juneid, As-Syibli, An-Nablusi, Abu Madyan, AsSyadzili, Al-Izz b. Abdussalam, As-Subki, Al-Isnawi (As-Sya'rani, Al-Yawaqit wa Al-Jawahir, Maktabah Al-Halabi, Kairo, cet terakhir, 1959, h. 14-15)

51 | Volume 13, No. 1, Januari-Juni 2017 
skripturalis dan menjauhi takwil. Dia adalah ulama yang memiliki kepribadian mengagumkan: hidup sederhana, wara', asketis dan sosok ulama yang tak pernah lepas dari dzikir ${ }^{39}$ dan terutama fatwa jihad serta sikap heroiknya melawan serangan Tar-tar, yang berhasil meruntuhkan ibu kota Abbasia di Baghdad.

\section{PENUTUP}

Kelompok anti-Sufi semestinya menyadari bahwa dinginnya dinding penjara telah membentuk karakter Ibn Taimiyah menjadi dingin dan $\operatorname{keras}^{40}$. Ambivalensi dalam tulisan-tulisan Ibn Taimiyah terkait Sufi juga sangat membingungkan bagi para pengkajinya. Fakta ini disadari oleh Al-Uraifi dan Musthafa Hilmi yang merasa kesulitan untuk mengidentifikasi secara jernih sikap Ibn Taimiyah terhadap kaum Sufi.

Pengalaman Ibn Taimiyah juga menegaskan bahwa seorang ulama yang mengambil jalur berbeda dari mainstream dan kerap menyalahi ijma' dengan inovasi ijtihadnya tak bisa diperlakukan sebagai kriminal. Kita harus menciptakaan nuansa saling menghormati dan melawan argumentasi dengan argumentasi, bukan dengan kekerasan. Memenjarakan seorang intelektual karena alasan kritik pedasnya adalah petaka. Penguasa tak boleh mengintervensi dan harus memberi ruang pada intelektual yang lain untuk mengetengahkan argumentasi berbeda.

Sebenarnya masih banyak tradisi sufistik yang dikritisi oleh Ibn Taimiyah dan kelompok anti-Sufi setelahnya. Dalam pembacaan penulis, setidaknya ada tiga pintu utama yang memungkinkan untuk dimasuki oleh kelompok anti-Sufi: pertama, institusi tarekat, kedua, sumber pengetahuan yang didapat dari ilham, ketiga, dualisme dzahirbatin atau syariat-hakikat dalam doktrin Sufi.

Ketiga pintu utama inilah yang kemudian dimasuki untuk menyesatkan kaum Sufi, hingga menjalar ke hampir semua tradisi sufistik. Namun saya memutuskan untuk mencukupkan pembahasan

\footnotetext{
${ }^{39}$ Al-Uraifi, Op cit, h. 32

${ }^{40}$ Ibrahim Uqaili, Op cit, h. 98

52 | Volume 13, No. 1, Januari-Juni 2017
} 
artikel ini hanya pada pintu pertama: tarekat. Karena image tarekat Sufi yang dianggap representasi paling mutakhir mengenai sufisme, disamping khazanah kekayaan turast sufistik.

Semoga makalah singkat ini bisa sedikit menguak kesadaran dialektis dan kerapuhan metodologis yang dipakai Ibn Taimiyah dalam mengkritisi tasawuf. Sebuah lorong gelap yang kemudian mencoba dilalui oleh kelompok anti-Sufi setelahnya dengan mata tertutup. Bahkan Muhammad bin Abdul Wahhab, pendiri Wahhabiyah, dalam buku risalahnya seakan hanya merekam ulang argumentasi dan sikap Ibn Taimiyah. ${ }^{41}$ Seandainya, Ibn Taimiyah memang benar ${ }^{42}$ tatkala mengilustrasikan kaum Sufi di masanya, maka fatwa yang dibubuhkan dalam buku-bukunya sangat kondisional dan bersifat lokal. Tak dibenarkan, menarik fatwa di masa silam ke masa kini karena menyalahi metode fatwa yang disepakati.

Sudah bukan zamannya lagi, seorang intelektual muslim melihat perbedaan dan kelompok lain sebagai evil. Apalagi dengan mengarang cerita bahwa kaum sufi lebih berbahaya dari non-muslim; ibarat rubah berbulu domba yang menyusup ke dalam Islam. Saatnya memupuk kepercayaan dan saling memahami. Kritik yang tidak sampai pada titik mengkafirkan sah-sah saja diberikan dan sangat dianjurkan agar bisa instropeksi diri.

\footnotetext{
${ }^{41}$ Baca: Muhammad b. Abdul Wahhab, Aqidat Firqah An-Najiyah dan Mufid AlMustafid, ed. Abdullah Hajjaj, Syirkah As-Salam Al-Alamiyah, Dokki-Mesir, t. t., h. 162-218 (Yang mengagetkan saya saat membaca buku ini adalah terma "kafir" yang disebut dalam setiap lembarnya, bukan hanya sekali. Padahal buku ini hanya setebal 56 halaman)

42 Ibn Taimiyah sering mengeluarkan fatwa sesat tanpa mempertimbangkan sosiokultural yang melingkupinya. Semisal fatwa kesesatan Al-Hallaj dan pengikutnya, semestinya dia membaca sejarah bagaiamana Ibn Suraih menolak untuk memberi fatwa eksekusi mati terhadap Al-Hallaj. Al-Hallaj dipenggal karena pertimbangan politik dan sosial (lihat: Ali Anjab As-Sa'i Al-Baghdadi, Akhbar Al-Hallaj, Dar AtThali'ah Al-Jadidah, Damaskus, 1997, cet II, h. 92)
}

53 | Volume 13, No. 1, Januari-Juni 2017 


\section{DAFTAR PUSTAKA}

Baghdadi (al), Ali Anjab As-Sa'i, Akhbār Al-Hallāj, Dar At-Thali'ah Al-Jadidah, Damaskus, 1997.

Ghazali (al), Abu Hamid, Al-Munkiz̄ min Ad-Dālal, dalam kompilasi buku Majmuat Rasa'il Al-Ghazali, Dar As-Syatibi, Kairo, cet I, 2010.

Ghurab (al), Mahmud, Syarh Kalimāt Șufiyah; Ar-Rad 'Ala Ibn Taimiyah, Matba'ah Nadlr, cet II, 1993.

'Itr, Nuruddin, Manhaj An-Naqd fi 'Ulum Al-Hadis, Dar Al-Fikr, Beirut, cet XXIII, 2008.

Jauzi (al), Abu Faraj, Talbis Al-Iblis, Maktabah Al-Mutanabbi, cet II, $1368 \mathrm{H}$.

Jhon O. Vall, Contemporary Sufism and Current Social Theory, dalam kompilasi buku bertajuk Sufism and The 'Modern' in Islam, Ed. Martin V. Bruinessen \& Julia Day Howell, I. B. Tauris \& Co Ltd, London, 2007, Mahmud al-Ghurab, Muqaddimah Rasāil Ibn Arabi, Dar Shader, Beirut, cet I, 1997.

Julia Day Howell \& Martin V. Bruinessen, Sufism and The 'Modern' in Islam, I. B. Tauris \& Co Ltd, London, 2007.

Kurdi (al), Muhammad Najmuddin, Ad-Dalāil Al-'Äliyah, Dicetak oleh pengarang, Kairo, cet I, 2008.

Laffan, Michael, National Crisis and The Representation of Traditional Sufism in Indonesia: The Periodicals Salafy and Sufi, dalam kompilasi buku bertajuk Sufism and The 'Modern' in Islam, Ed. Martin V. Bruinessen \& Julia Day Howell, I. B. Tauris \& Co Ltd, London, 2007.

Nassar (al), Ali Sami dalam Nasy'at Al-Fikr Al-Falsafi fi Al-Islam, Dar As-Salam, Kairo, Vol III, cet I, 2008

Nicholson, As-Șufiyah fi Al-Islam, diarabkan oleh Nuruddin Syarribah, Maktabah Al-Khanji, Kairo, cet II, 2002

Samuli Schielke \& Georg Stauth, Dimensions of Locality; Muslim Saint, Their Place and Space, Gutenberg Univ., Jerman, 2008.

Syafi'i (al), Hasan, Al-Madkhal Ila Dirasāt 'Ilmi Al-Kalām, Maktabah Wahbah, Kairo, cet II, 1991.

Sya'rani (al), Al-Yawaqit wa Al-Jawāhir, Maktabah Al-Halabi, Kairo, cet terakhir, 1959

Uqaili, Ibrahim, Takāmul Al-Manhaj 'Inda Ibni Taimiyah, The International Institute of Islamic Thought, Herdon-Virginia, cet I, 1994.

54 | Volume 13, No. 1, Januari-Juni 2017 
Uraifi (al), Muhammad Abdurrahman, Mauqï Ibn Taimiyah min AsSufiyah, Vol I, cet I, Dar Al-Minhaj, Riyadl, $1430 \mathrm{H}$.

Wahhab, Muhammad b. Abdul, Aqidat Firqah An-Najiyah dan Mufid Al-Mustafid, ed. Abdullah Hajjaj, Syirkah As-Salam AlAlamiyah, Dokki-Mesir, t. t., h.

Wahhab, Muhammad Hilmi Abdul, Wulat wa Awlia As-Sulthah wa Al-Mutashawwifah fi Islam Al-Assr Al-Wasit, As-Syabakah AlArabiyah li Al-Abhast wa An-Nasyr, Beirut, cet I, 2009. 